\title{
Morphology of the pore space in claystones - evidence from BIB/FIB ion beam sectioning and cryo-SEM observations
}

\author{
G. Desbois ${ }^{1}$, J. L. Urai ${ }^{1}$, and P. A. Kukla ${ }^{2}$ \\ ${ }^{1}$ Geologie - Endogene Dynamik, RWTH Aachen University, Lochnerstr. 4-20, 52056 Aachen, Germany \\ ${ }^{2}$ Geological Institute, RWTH Aachen University, Wüllnerstr. 2, 52062 Aachen, Germany
}

Received: 2 December 2008 - Published in eEarth Discuss.: 3 February 2009

Revised: 15 May 2009 - Accepted: 30 June 2009 - Published: 8 July 2009

\begin{abstract}
The morphology of pore space has a strong effect on mechanical and transport properties of mudrocks and clay-rich fault gouge, but its characterization has been mostly indirect. We report on a study of Boom clay from a proposed disposal site of radioactive waste (Mol site, Belgium) using high resolution SEM at cryogenic temperature, with ion beam cross-sectioning to prepare smooth, damage free surfaces. Pores commonly have crack-like tips, preferred orientation parallel to bedding and power law size distribution. We define a number of pore types depending on shape and location in the microstructure: large jagged pores in strain shadows of clastic grains, high aspect ratio pores between similarly oriented phyllosilicate grains and crescent-shaped pores in saddle reefs of folded phyllosilicates. 3-D reconstruction by serial cross-sectioning shows 3-D connectivity of the pore space. These findings offer a new insight into the morphology of pores down to nano-scale in comparison to traditional pore size distributions calculated from mercury Injection experiments, explain slaking of clays by successive wetting and drying and provide the basis for microstructurebased models of transport in clays.
\end{abstract}

\section{Introduction}

Mudrocks and clay-rich fault gouges are important mechanical elements in the Earth's crust and form seals for crustal fluids such as groundwater and hydrocarbons. Other fields of interest are the storage of anthropogenic carbon dioxide and radioactive waste in geologic formations. In addition, coupled flows, capillary processes, and associated deformation are of importance in many applied fields, (Heidug and Wong,

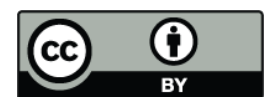

Correspondence to: G. Desbois (g.desbois@ged.rwth-aachen.de)
1995; Mitchell, 1993). A key factor to understanding these processes is a detailed understanding of the morphology of the pore space.

Classic studies of porosity in fine grained materials are performed on dried or freeze dried samples and include metal injection methods (Hildenbrandt and Urai, 2003), magnetic susceptibility measurement (Esteban et al., 2006), SEM (Hildenbrandt et al., 2005) and TEM imaging (Henning and Störr, 1986); but also neutron scattering (Knudsen et al., 2003), nuclear magnetic resonance (NMR) spectroscopy (Sozzani et al., 2006), and environmental SEM (ESEM, Montes et al., 2005). Confocal microscopy (Fredrich et al., 1995) and X-ray tomography (Zabler et al., 2008) are used to image porosity in coarse grained sediments but the resolution of these techniques is not sufficient at present for applications to mudrocks or clay-rich fault gouges. Therefore, observations and interpretations remain difficult because none of these approaches is able to directly describe the in-situ porosity at the pore scale. In addition, some methods require dried samples in which the natural structure of pores may have been damaged to some extent due to desiccation and dehydration of the clay minerals.

A recently developed alternative is to study wet samples using a high-resolution cryogenic SEM, which allows stabilization of wet media at cryo-temperature, in-situ sample preparation by ion beam cross-sectioning (Broad Ion Beam or Focussed Ion Beam; BIB, FIB) and observations of the stabilized microstructure at high resolution (Desbois et al., 2008; Matthijs de Winter et al., 2009).

We applied the cryo-FIB-BIB-SEM method to investigate porosity in undisturbed samples of Boom clay (Mol site, Belgium), a proposed site of nuclear waste disposal (Boisson, 2005). We show that the FIB-cryo-SEM is an efficient method to study the undisturbed pore space at high resolution and suggest a simple model for porosity in Boom clay.

Published by Copernicus Publications on behalf of the European Geosciences Union. 

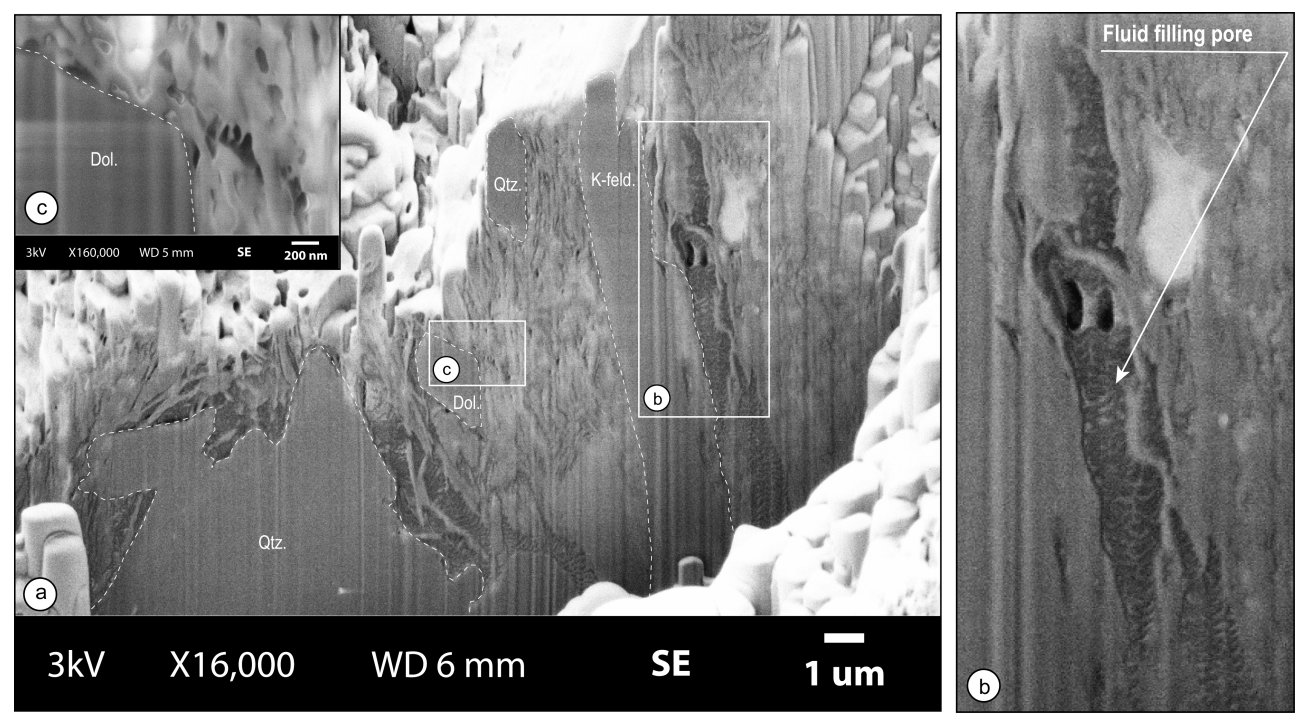

Fig. 1. SEM image of FIB cross-section in Boom clay. In-situ fluids are clearly visible in the biggest pores. (a) Overview of the cross-section: the biggest pores are located around the non-clay minerals (Quartz=Qtz, Dolomite=Dol., K-Feldspar= K-feld) and the smallest pores in the clay aggregates (b) Focus on in-situ fluid. Grainy structures are due to the presence of organic matter in the fluid. (c) Focus on small pores region. Due to the sublimation effect related to the beam energy concentration at high magnification, these pores appear free of fluids.

\section{Materials and methods}

We used undisturbed clay samples of Boom clay (Mol, Belgium, collected at depth $5.82 \mathrm{~m}-5.98 \mathrm{~m}$ above the HADES URF, Appendix A). Samples were sealed in aluminium safety bags directly after the sampling to preserve samples against dehydration and oxidation. A comprehensive summary of physical and chemical properties of Boom clay is given in Boisson (2005). We used a Zeiss FIB-cryo-SEM combination in NMI (Naturwissenschaftliches und Medizinisches Institut, Reutlingen, Germany) as described in Desbois et al. (2008), and a high resolution SEM and BIB at GFE, RWTH Aachen. Nitrogen was used to rapidly cool small samples (about $5 \times 5 \times 1 \mathrm{~mm}^{3}$, Appendix B) to vitrify in-situ pore fluids. The FIB ion-milling tool located in the cryo-SEM chamber was used to prepare polished crosssections and serial cross-sectioning, prior to high resolution imaging of porosity by cryo-SEM. For comparison we studied polished cross-sections (about $2 \mathrm{~mm}^{2}$ ) from dried samples (at $T=105-110^{\circ} \mathrm{C}$ ) prepared using a stand-alone BIB machine (cross-section polisher JEOL SM-09010; we used $6 \mathrm{kV}$ voltage, achieving currents of about $150-200 \mathrm{nA})$. Water content of our samples is $19-20 \mathrm{wt}$. \% (i.e. water content porosity around $36 \%$ ), in good agreement with the value in Boisson (2005); hence shrinkage during drying was around $10 \%$ in volume.

\section{Results}

\subsection{Vitrified fluids in pores}

Figure 1 shows a FIB-polished cross section (around $20 \times 15 \mu \mathrm{m}^{2}$ ) of a shock-frozen sample. There is no visible damage, and one clearly observes non-clay minerals surrounded by large pores and clay mineral aggregates containing smaller pores. Imaging the vitrified fluid is problematic at the highest magnification since the energy of the beam sublimes the fluids before an image can be recorded.

\section{2 $\quad$ Freeze-drying}

Cryo-stabilization is a fundamental step to stabilize pore microstructures without damage and to image the pore fluid. However, the presence of fluid in pores is not required to study the morphology of porosity because an empty pore provides better SE contrast and a 3-D view into the exposed pore. Hence, freeze-drying was performed by heating the vitrified sample after FIB sectioning, in the SEM chamber and under vacuum. Figure 2 shows the area presented in Fig. 1 after freeze-drying $\left(-130^{\circ} \mathrm{C}\right.$ to $-80^{\circ} \mathrm{C}$ during $20 \mathrm{~min}$., at $8 \times 10^{-7} \mathrm{mbar}$ ). The fluid is removed from the pores, again without visible change of the grain microstructure. In the largest pores (Fig. 2) a nicely organized network of organic matter filaments remains: this material is interpreted to have been dissolved in the pore fluid. 

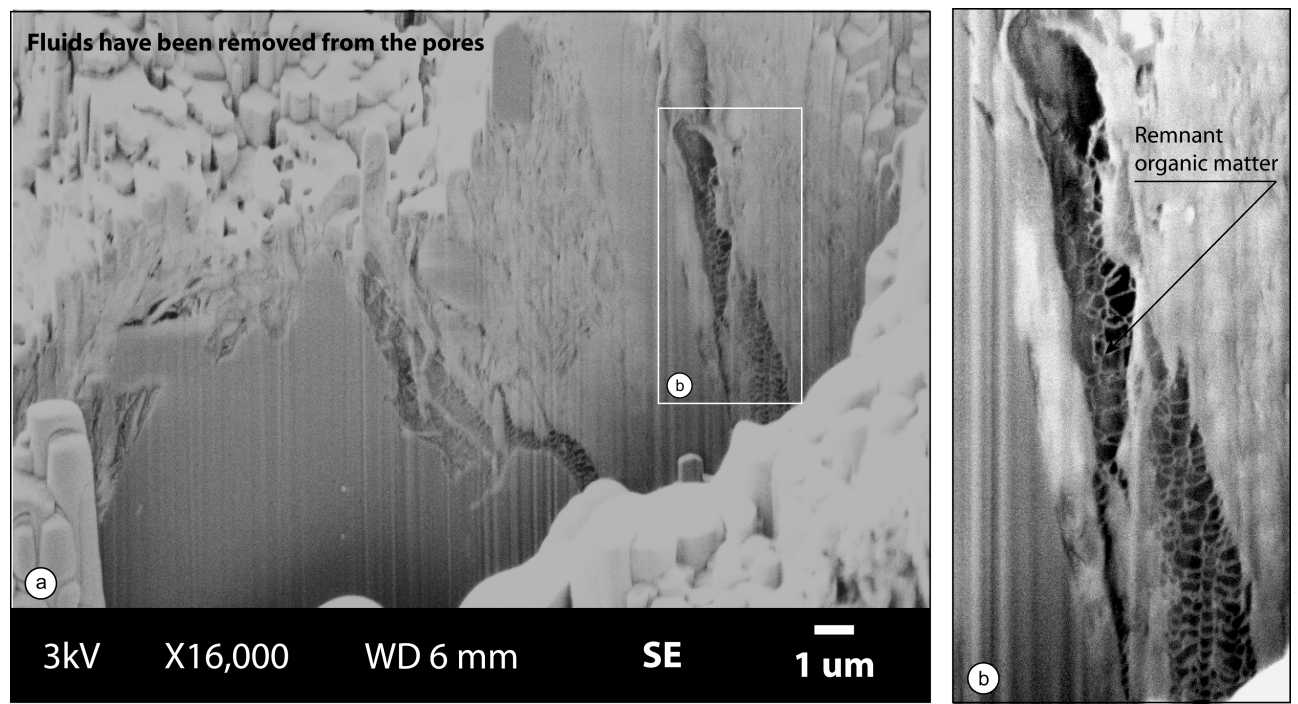

Fig. 2. Freeze drying of the FIB cross-section presented in Fig. 1. (a) Overview of the cross-section: the sublimation has removed fluids from the pores without damages of microstructures. (b) Focus on freeze-dried big pore. This pore is now free of fluid; the other phases were distilled during sublimation and remains as filaments.

\subsection{Morphology of individual pores}

Figure 3 shows BSE and SE images of a dry sample sectioned by BIB. Drying and shrinkage reduce porosity, but we found no indication of changes in pore morphology by drying. As shown in Figs. 1 and 2, the largest pores are located around clast grains while the smallest are preferentially located between clay particles. Pores are preferentially oriented parallel to the bedding. SE imaging (Fig. 3) provides information on the morphology of the jagged pore walls and pore interiors. As far as can be seen in these sections, small pores are isolated while large pores show the pore throats connecting to neighboring pores. Pores commonly have sharp, cracklike tips. We distinguished 3 main types of pore morphology: (1) Type I - elongated pores between similarly oriented clay sheets, (2) Type II - crescent-shaped pores in saddle reefs of folded sheet of clay and (3) Type III - large jagged pores surrounding clast grains. Type III pores are typically $>1 \mu \mathrm{m}$; Type II between $1 \mu \mathrm{m}-100 \mathrm{~nm}$ and Type $\mathrm{I}<100 \mathrm{~nm}$, in agreement with the microstructural model of mudstones proposed by Hildenbrandt et al. (2005).

\subsection{Statistics on porosity and fractal dimension}

FIB- polished cross sections (about $10 \mu \mathrm{m}^{2}$; Fig. 4a) cut perpendicular to bedding and freeze-dried in the SEM allow the distribution, orientation and shape of pores to be determined by imagery. Noise was reduced and the images were threshold using Photoshop 8.0 followed by analysis using the ImageJ $1.38 \times$ - software (Abramoff et al., 2004). Objects less than 6 pixels in area (pixel dimension is $12.5 \mathrm{~nm}$ ) were interpreted as noise and not included in the analysis.
Results are summarized in Fig. 4 for a population of 2320 pores. The distribution of pores is unimodal, $87 \%$ of the pores have an equivalent radius less than $100 \mathrm{~nm}$ and the total porosity is $20.4 \%$. Pores with a radius less than $100 \mathrm{~nm}$ comprise $40 \%$ of the total porosity. The shape of the pores is mainly elongated (average form factor 0.59 ) and orientation is close to the bedding. The porosity resolved in this image can be fitted by a power law (Appendix C) for pore sizes between $r_{\min }=37.5$ and $r_{\max }=125 \mathrm{~nm}$ (Fig. 4e). This suggests fractal scaling of the pore space in Boom clay. The power law exponent (fractal dimension) is between 1.78 and 1.90, depending on the exact choice of $r_{\max }$. A similar approach was also used for the dried sample (Fig. 3a) with a porosity of $26.3 \%$ and a fractal dimension ranging from 1.82 and 1.91 for pore size between $r_{\min }=12$ and $r_{\max }=35 \mathrm{~nm}$.

\subsection{Anisotropy of pore space distribution}

SEM imaging on large $\left(800 \times 260 \mu \mathrm{m}^{2}\right)$ BIB polished crosssections on dried Boom clay samples (cut perpendicular to bedding) shows a strong anisotropy of the pore shapes, the pore network being mainly connected parallel to the bedding. In order to study the undisturbed wet pore space in 3-D, a serial cross-sectioning procedure was performed using the FIB-cryo-SEM. Resulting slices are $500 \mathrm{~nm}$ thick. Figure 5 shows the reconstruction of the porosity in depth (over $3 \mu \mathrm{m}$ ) around a quartz grain. It confirms the strong connectivity anisotropy observed in dried samples and gives direct evidence that the largest pores surrounding the quartz grains form a connected "backbone" of $100 \mathrm{~nm}$ to several microns thick mainly oriented parallel to bedding. Interconnectivity is difficult to analyze for the smallest pores because of 

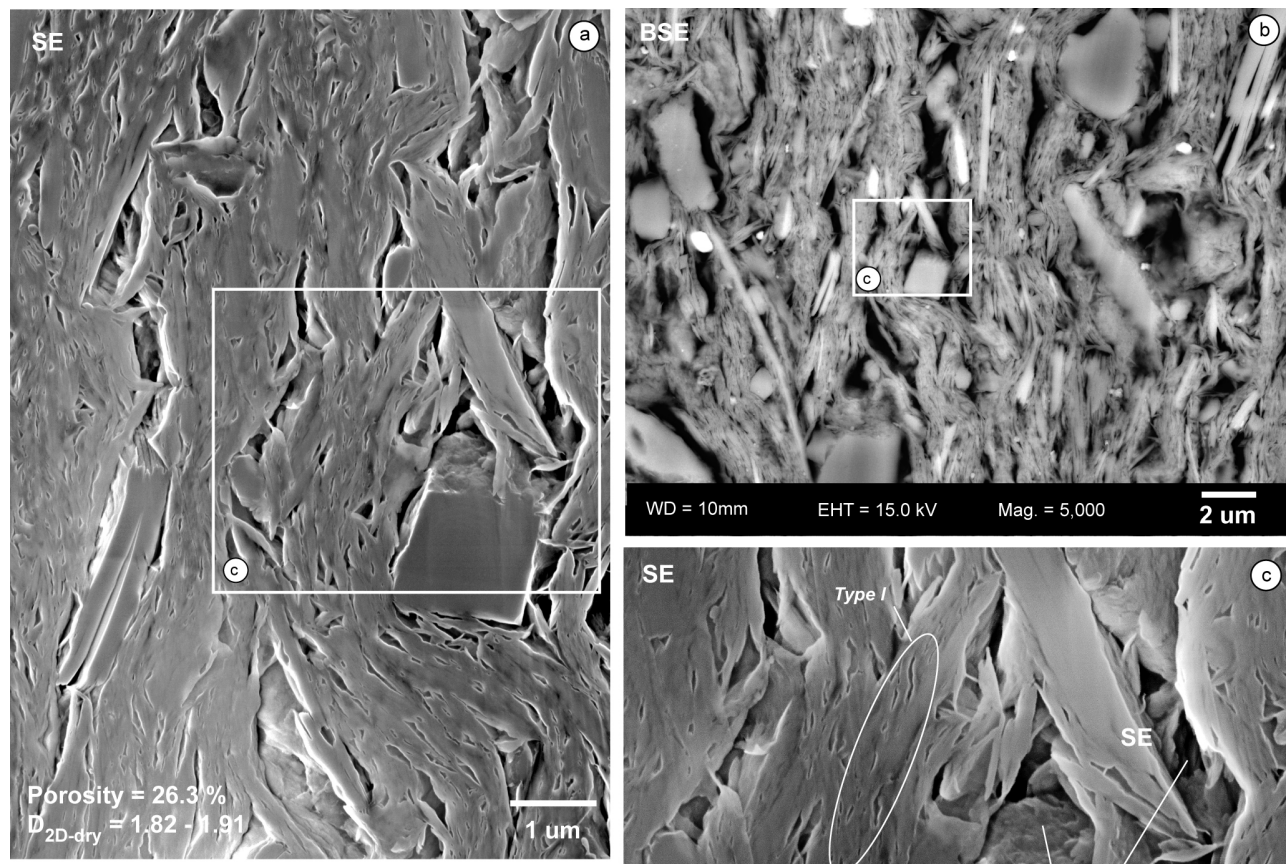

Type I: Elongated pores between similarly oriented clay sheets

Type II: Crescent-shaped pores in saddle reefs of folded sheet of clay

Type III: Large jagged pores surrounding clasts

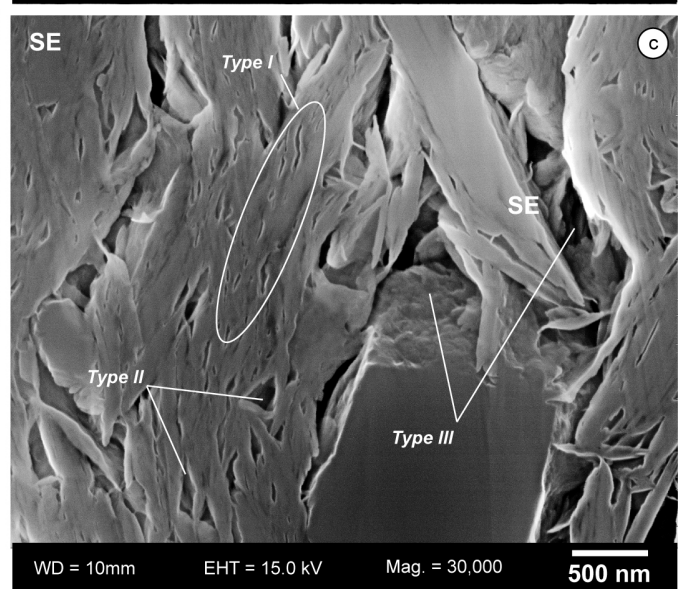

Fig. 3. SEM images of BIB cross-section on dried Boom-clay, perpendicular to the bedding. (a) SE image used to measure the visible porosity $(=26.3 \%)$ and the fractal dimension (1.82-1.91). (b) BSE image allowing identification of minerals phases. (c) SE image showing the three types of pore morphology identified in our sample (see details on figure). In all images, the bedding is vertical.

aliasing (the current distance between slices is $500 \mathrm{~nm}$, but this can be reduced to less than $20 \mathrm{~nm}$ ).

\section{Discussion and conclusions}

\subsection{Validation of the BIB-FIB-cryo-SEM approach}

The use of the BIB-FIB milling tools obviously produces very high quality cross-sections without damage to investigate the pore network at high resolution without damage and fine slices for 3-D reconstruction allowing investigation of the pore network of mudrocks at high resolution. This contribution confirms that plunge-freezing in nitrogen wellfreezes the pore fluids and that the cooling-rate is fast enough to avoid the formation of ice crystals which tend to damage the microstructure (Karlsson, 2002). Vitrification in nitrogen is an accepted technique for freezing biological samples without damage (Echlin, 1978; Marko et al., 2007). Up to now, cryo-SEM applications in Geosciences are restricted to fluid inclusions and wettability studies (Mann et al., 1994; Schenk et al., 2006; Vizika et al., 1998) without demon- strating the efficiency of the vitrification. Delage and Pellerin (1984) for clays and Desbois et al. (2008) for wet halite have demonstrated that samples about $1 \mathrm{~mm}$ thick as used in our experiments offer a good compromise between the workable sample volume and geometrical considerations to vitrify the fluids. Although, vitrification of our samples is not fully validated, the present observations agree with the absence of damage. Further work on demonstrating this is in progress

\subsection{Porosity}

Our SEM - measured porosity $\left(\phi_{\text {cryo-SEM }}=20.4 \%\right.$ in freeze dried samples, $26 \%$ in dried samples) agrees quite well the porosity based on mercury porosimetry data $\left(\phi_{H g}=24-27 \%\right.$ in dried samples) for similar Boom clay samples though our measurement based on cryo-SEM experiment trends to give a lower porosity value. However, our SEM-measured porosity is much lower than the water content porosity $\left(\phi_{W C}=36 \%\right.$; Boisson, 2005). Several reasons explain this discrepancy. First, the resolution of the SEM is about $10 \mathrm{~nm}$ although pores as small as $0.5 \mathrm{~nm}$ do exist as shown by other methods including mainly TEM. Extrapolation of the power law 

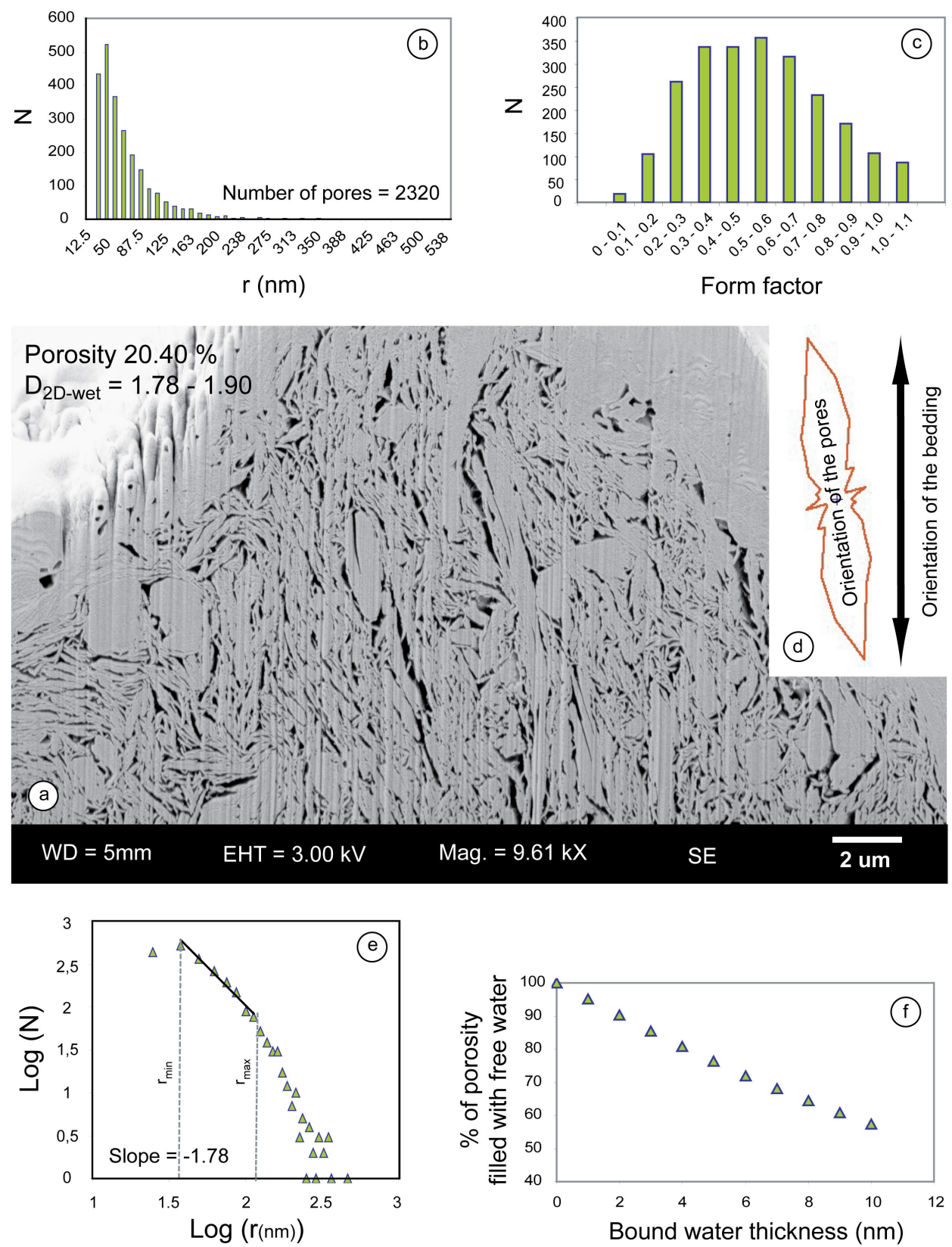

Fig. 4. Statistical study of the porosity in Boom clay inferred by cryo-SEM. (a) SEM image of the studied area, (b) Number of pore as a function of the pore size, (c) Form-factor distribution, (d) orientation of the pores, (e) fit of a power law model to our data and (f) evolution of the porosity as a function of bound-water layer thickness. $N$ is the number of pores.

pore size distribution to values below the limit of resolution suggests that e.g. a sample with $20 \%$ resolved porosity has $2 \%$ porosity not resolved by this method. In addition, the tips of crack-shaped pores and the films of clay-bound water at grain boundaries and inside smectite grains are also not resolved fully; accounting for this gives another $8 \%$. Thus, although our FIB-cryo-SEM approach is suitable for investigation of meso-porosity only, by making reasonable assumptions we can estimate the full porosity. However, for our freeze-dried sample this is still much lower than the average value of $\phi_{W C}=36 \%$. In the dried sample, after correction for the unresolved pores and keeping in mind the possible artifacts produced by mercury injection such as pore collapse (Hildenbrand and Urai, 2003; Majling et al., 1995) the porosity is in reasonable agreement with the water-contentporosity. We interpret this discrepancy to be due to the size of the analyzed samples. Mercury injection and water content measurement are typically performed on $\mathrm{cm}^{3}$ samples 


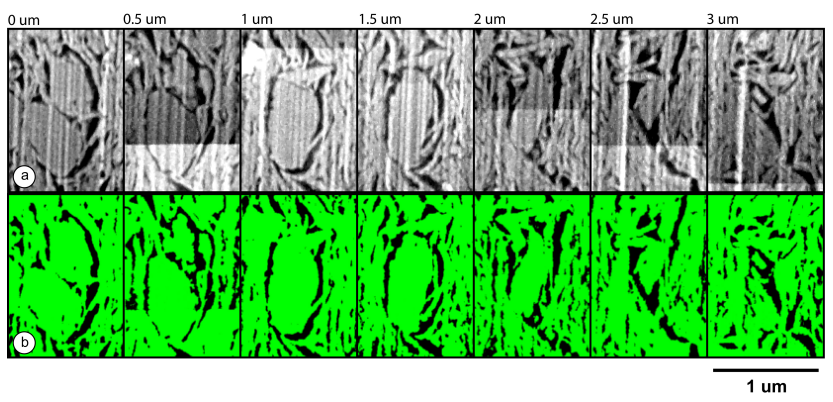

Fig. 5. FIB serial cross-sections around a quartz grain in Boomclay, perpendicular to the bedding. The slice thickness is $500 \mathrm{~nm}$. (a) Initial SE pictures and, (b) segmented pictures. The porosity is mainly connected along the direction parallel to the bedding.

and the areas analyzed here are on the order of $10 \mu \mathrm{m}^{2}$. The size of a representative elementary volume for porosity in Boom clay is still to be determined, but future representative measurements will require study of larger sections.

\subsection{Fractal dimension and pore space modeling}

For the fractal dimension of the 2-D apparent porosity we get similar results on dried and wet samples. This suggests that the shrinkage affects the volume of pores but not their size distribution. The calculated fractal dimension $(D=1.8-$ 1.9) is valid in the range between 12 and $125 \mathrm{~nm}$. Geological porous media (Daccord and Lenormand, 1987; Krohn and Thompson, 1986; Rieu and Sposito, 1991) have been shown to have a fractal distribution of porosity. This paper is the first evidence that porosity in a clay material has a fractal distribution, and demonstrates the usefulness of our BIB/FIB-cryo-SEM technique for meso-porosity investigation in such rocks. The calculated fractal dimension $(D=1.8-1.9)$ is close to the fractal dimension of the Sierpinsky's carpet $(D=1.89)$. In Rieu and Sposito (1991) it is suggested that soils may be modeled by the Menger's sponge ( $D=2.73)$, which is the 3-D version of the Sierpinsky's carpet. Unfortunately, the observation of the strong anisotropy of the pore distribution and the interconnectivity (Fig. 5) does not corroborate this simple suggestion for Boom-clay.

\subsection{Implications}

The high slaking tendency of argillaceous rocks increases with the content in smectite content and with the presence of soluble minerals (Sadisun et al., 2005). We propose that the flat, crack-like pore morphology will induce high capillary forces in these pore- tips if a dry sample is re-wetted, resulting in mechanical damage and destruction of the fabric by successive drying and wetting.

It is well known that water content porosity in claystones does not reflect the effective porosity (i.e. the porosity accessible to free-water) because thin layers of clay-bound water cover the pore-walls (Saarenketo, 1998). Figure 4d shows a model of effective porosity in our samples as a function of the bound-water layer thickness, using the segmented image from Fig. 4a. We can see that increasing the thickness of the boundwater layer decreases the effective porosity as a semi-linear function, suggesting that with increasing bound-water layer thickness pores usually do not segment into smaller ones. Following (Saarenketo, 1998; Nakashima and Mitsumori, 2005) typical bound water is $2-6 \mathrm{~nm}$ thick. Thus, the effective porosity represents between 90 and $70 \%$ of the porosity imaged in this paper (clay bound water is also present in the pores too small to be imaged).

\subsection{The potential of the BIB-FIB-cryo-SEM method}

Application of the BIB-FIB-cryo-SEM method to study the porosity in clay-rich materials is clearly relevant for waste disposal, hydrocarbon production, basin modeling, fault zone studies and others. It has the potential to open a new field of investigations, producing an atlas of accurate, 3-D pore models of mudstones. This method offers a powerful combination for direct and in-situ investigations of the elusive structures in clay materials at pore scale opening a new field of investigations to study relation between nanostructures and macro-properties which are poorly understood at present. As far as we know, this is the first time that fluids were directly imaged in in-situ conditions in mudrocks, offering new insights for the study of fluid- rock interaction (osmotic effect, ion exchange, pore alteration), especially if the BIB-FIB-cryo-SEM is coupled to chemical composition analysis tool (EDX, SIMS). The reduction of the slice thickness (down to $20 \mathrm{~nm}$ ) will produce high-resolution models of pore space with the possibility to model fluid flow and microstructure-based models of transport in clays (Fredrich and Lindquist, 1997; Bons et al., 2008). This will provide a unique opportunity to model the flow through in-situ pore network, study the in-situ effective interconnectivity and verify the viability of our proposed clay fractal model.

\section{Appendix A}

\section{The exact reference of the Boom clay sample}

Boom clay/Mol site/HADES borehole 2003-9/connecting gallery/Ring $13 \mathrm{U} / 5.82 \mathrm{~m}$ to $5.975 \mathrm{~m}$ above the Hades URF (intrados).

\section{Appendix B}

The procedure for the preparation of the small Boom clay samples

In order to achieve a rapid cooling for efficient vitrification and to fit the SEM-sample holder dimension, the Boom clay 
samples were prepared in small pieces (about $5 \times 5 \times 1 \mathrm{~mm}^{3}$ ). Because the Boom clay material is soft but brittle, the small samples can be easily split from a larger block by fracturing initiated with a fine scalpel notch and in few minutes to minimize the dehydration. This procedure provides small samples without any visible damage at the pore scale.

\section{Appendix C}

\section{Definition of the 2-D apparent fractal dimension}

Fractals concept has been also applied to describe the distribution of 2-D apparent pore cross sections. Any fractal feature is characterized by a (Haussdorf) fractal dimension $D$ which can have any value between 0 and the Euclidian dimension in which the object is embedded (Ruffet et al., 1991; Feder, 1988). A fractal set is defined by the following equation (Pfeifer and Obert, 1989): $N_{i}=C / r_{i}^{D}$ (or alternatively $\log \left(N_{i}\right)=-D \log \left(r_{i}\right)+\log (C)$, Eq. 1$)$ where Ni is the number of pores with the characteristic linear dimension ri (i.e., here, the disk equivalent radius), and $C$ is a constant of proportionality. According the Eq. (1), the fractal dimension was obtained as the slope of the Log-Log plot of measured $N_{i}$ as a function of $r_{i}$. Systematic deviations from the power law form define the range where the fractal dimension is valid defined by the length scales $r_{\min }$ and $r_{\max }$. At shortlength extremes, the data are limited by the microscope resolution and the picture's noise; at long-length extremes, the data are limited by the fact that the investigated area is not endlessly.

Acknowledgements. We thank Christoph Nussbaum and Mieke de Craen of SCK-CEN for help with obtaining the Boom clay samples. We are grateful to Claus Burkhardt (NMI at university of Tübingen, Reutlingen, Germany), Alexander Schwedt (GFE at RWTH, Aachen University, Aachen, Germany) for their technical support for the SEM imaging and Jochen Hürtgen for image processing. The authors thank also J. L. Bouchez (LMTG, Toulouse university) for his comments used to improve the manuscript. This project was funded by the Deutsche Forschungsgemeinschaft (UR 64/9-2).

Edited by: J. Smit

\section{References}

Abramoff, M. D., Magelhaes, P. J., and Ram, S. J.: Image Processing with ImageJ, Biophotonics International, 11(7), 36-42, 2004.

Boisson, J. Y.: Clay Club Catalogue of Characteristics of Argillaceous Rocks, OECD/NEA/RWMC/IGSC (Working Group on measurement and Physical understanding of Groundwater flow through argillaceous media) august 2005 Report NEA no. 4436 (Brochure and CD-Rom including data base), OECD/NEA Paris, France, p. 72, 2005.

Bons, P. D. D., Koehn, D., and Jessell, M. W.: Microdynamics Simulation. Series: Lecture Notes in Earth Sciences, Vol. 106, edited by: Bons, P. D. D., Koehn, D., and Jessell, M. W., XXII, p. 406, ISBN:978-3-540-25522-2, 2008.

Daccord, G. and Lenormand, R.: Fractal patterns from chemical dissolution, Nature, 325, 41-43, 1987.

Delage, P. and Pellerin, F. M.: Influence de la lyophilisation sur la structure d'une argile sensible du Quebec, Clay Minerals, 19, 151-160, 1984.

Desbois, G., Urai, J. L., Burkhardt, C., Drury, M. R., Hayles, M., and Humbel, B.: Cryogenic vitrification and 3-D serial sectioning using high resolution cryo-FIB SEM technology for brinefilled grain boundaries in halite: first results, Geofluids, 8(1), 60-72, 2008.

Matthijs de Winter, D. A., Schneidjdenberg ,C. T. W. M., Lebbink, M. N., Lich, B., Verkleij, A. J., Drury, M. R., and Humbel, B. M.: Tomography of insulated biological and geological materials using focused ion beam (FIB) sectioning and low-kV BSE imaging, J. Microscopy, 233, 372-383, 2009.

Echlin, P.: Low temperature scanning electron microscopy: a review, J. Microscopy, 112(1), 47-61, 1978.

Esteban, L., Géraud, Y., and Bouchez, J. L.: Pore network geometry in low permeability argillites from magnetic fabric data and oriented mercury injections, Geophys. Res. Lett., 33, L18311, doi:10.1029/2006GL026908, 2006.

Feder J.: Fractals, Plenum Press, New York, Collection: Physics of Solids and Liquids, p. 310, ISBN:978-0-306-42851-7, 1988.

Fredrich, J. T. and Lindquist, W. B.: Statistical characterization of the three-dimensional microgeometry of porous media and correlation with macroscopic transport properties, International journal of rock mechanics and miningl sciences, 34, 3-4, paper no. $085,1997$.

Fredrich, J. T., Menéndez, B., and Wong, T.-F.: Imaging the Pore Structure of Geomaterials, Science, 268, 276-279, doi:10.1126/science.268.5208.276, 1995.

Heidung, W. K. and Wong, S. W.: Hydration of swelling of waterabsorbing rocks: a constitutive model, International journal for numerical and analytical methods in geomechanics, 20, 403430, 1995.

Henning, K. H. and Störr, M.: Electron micrographs (TEM, SEM) of clays and clay minerals, Akademie-Verlag Berlin [Schriftenreihe für geologische Wissenschaften, Bd. 25], 352 pp., 1986.

Hildenbrand, A. and Urai, J. L.: Investigation of the morphology of pore space in mudstones - First results, Marine and Petroleum Geology, 20(10), 1185-1200, 2003.

Hildenbrand, A., Krooss, B. M., and Urai, J. L.: Relationship between pore structure and fluid transport in argillaceous rocks, Solid Mechanics and Its Applications, IUTAM Symposium on Physicochemical and Electromechanical Interactions in Porous Media, 125, 231-237, doi:10.1007/1-4020-3865-8 26. 2005.

Hunt, A. G.: Percolation Theory for Flow in Porous Media, Lecture notes in physics, 674, 203 pp., Springer, Germany, ISBN:978-3540-26110-0, 2005.

Karlsson, J. O.: Cryopreservation: freezing and vitrification, Science, 296, 655-656, 2002.

Knudsen, K. D., Fossum, J. O., Helgesen, G., and Bergaplass, V.: Pore characteristics and water absorption in a synthetic smectite clay, J. Appl. Crystallogr., 36, 587-591, 2003.

Krohn, C. E. and Thompson, A. H.: Fractal sandstone pores: Automated measurements using scanning-electron microscope images, Phys. Rev., B33, 6366-6374, 1986. 
Majling, J., Komarneni, 5 S., and Fajnor, V. S.: Mercury porosimeter as a means to measure mechanical properties of aerogels, Journal of porous materials, 1, 91-95, 1995.

Mann, U., Neisel, J. D., Burchard, W. G., Heinen, V., and Welte, D. H.: Fluid-rock interfaces as revealed by cryo-scanning electron microscopy, First break, 12(3), 131-136, 1994.

Marko, M., Hsieh, C., Schalek, R., Frank, J., and Mannella, C.: Focused-ion-thinning of frozen hydrated biological specimens for cryo-electron microscopy, Nature methods, 4, 215-217, doi:10.1038/nmeth1014, 2007.

Mitchell, J. K.: Fundamental of soil behaviour, Second edition, John Wiley and Sons, Inc. 437 pp. ISBN:0-471-85640-1, 1993.

Montes, H. G., Geraud, Y., Duplay, J., and Reuschle, T.: ESEM observations of compacted bentonite submitted to hydratation/dehydration conditions, Colloids and surfaces A: Physicochem, Eng. Aspects, 262, 14-22, doi:10.1016/j.colsurfa.2005.03.021, 2005.

Nakashima, Y. and Mitsumori, F.: $\mathrm{H}_{2} \mathrm{O}$ self-diffusion restricted by clay platelets with immobilized bound $\mathrm{H}_{2} \mathrm{O}$ layers: PSGE NMR study of water-rich saponite gels, Applied Clay Sciences, 28, 209-221, doi:101016/j.clay.2004.01.017, 2005.

Pfeifer, P. and Obert, M.: The fractal approach to hetererogeneous chemistry, edited by: Avnir, D., Wiley, Chischester, England, 11-43, 1989.

Rieu, M. and Sposito, G.: Fractal Fragmentation and Soil Water Properties: II. Applications, Soil Sciences Society of America, 55, 1239-1244, 1991.
Ruffet, C., Gueguen, Y., and Darot, M.: Complex conductivity measurements and fractal nature of porosity, Geophysics, 56(6), 758768, 1991.

Saarenketo, T.: Electrical properties of water in clay and silty soils, J. Appl. Geophys., 40, 73-88, 1998.

Sadisun, I. A., Shimada, H., Ichinose, M., and Matsui, K.: Study on the physical disintegration characteristics of Subang claystone subjected to a modified slaking index test, Geotechnical and Geological Engineeering, 23, 199-218, doi:10.1007/s10706-0036112-6, 2005.

Schenk, O., Urai, J. L., and Piazolo, S.: Structure of grain boundaries in wet, synthetic polycrystalline, statically recrystallizing halite - evidence from cryo-SEM observations, Geofluids, 6, 93104, 2006.

Sozzani, P., Bracco, S., Comotti, A., Mauri, M., Simonutti, R., and Valsesia, P.: Nanoporosity of an organo-clay shown by hyperpolariszed xenon and 2-D NMR spectroscopy, Chem. Commun., 1921-1923, doi:10.1039/b602040b, 2006.

Vizika, O., Rosenberg, E., and Kalaydjian, F.: Study of wettability and spreading impact in three-phase gas injection by cryoscanning electron microscopy, Journal of Petroleum Science and Engineering, 20, 189-202, 1998.

Zabler, S., Rack, A., Manke, I., Thermann, K., Tiedermann, J., Harthill, N., and Riesemeier, H.: High resolution tomography of cracks, voids and microstructures in greywacke and limestone, Journal of structural geology, 30(7), 876-887, 2008. 